\title{
AN EXPLORATION OF THE RELATIONSHIP BETWEEN TEACCH AND A MUSIC THERAPY STUDENT'S PRACTICE IN A SPECIAL EDUCATION SETTING
}

An exegesis presented in partial fulfilment of the requirements for a degree of Master of Music Therapy At the New Zealand School of Music, Wellington New Zealand

\author{
Philippa Algie
}

2012 


\section{$\underline{\text { Abstract }}$}

The purpose of this qualitative study was to explore how aspects of Schopler's TEACCH (Treatment and Education of Autistic and related Communication Handicapped Children) might be related to music therapy practice, using my own practice in an attached unit at a public primary school in New Zealand as a guide. Using a deductive exploratory research approach, I investigated whether and to what extent themes drawn from TEACCH literature were also evident in my music therapy data. This approach can also be described as secondary analysis of data. That is, clinical data relating to individual and group music therapy sessions with children who have autism was subjected to a process of thematic analysis to answer the research question.

The TEACCH philosophy advocates a structured teaching approach in order to support students with autism to develop independence and skills for self management. This study finds that many elements of music therapy practice are closely linked to TEACCH values. Results from the study show that many TEACCH strategies align with fundamental aspects of music therapy, but the frequency and consistency of these similarities can vary due to the diverse strengths and needs of individuals with autism. As the process of comparing the TEACCH literature to my clinical practice developed and changed, some aspects of TEACCH became more integrated within my music therapy practice. The study also highlights the importance of balancing structure and freedom within the work and how musical structure or form can link with TEACCH strategies. 


\section{Acknowledgements}

I would like to offer my sincere thanks to my research supervisor, Dr Daphne Rickson for her knowledge, advice and invaluable support.

Thank you to all my colleagues and friends in the music therapy field, especially Sarah Hoskyns, Carolyn Ayson and my fellow classmates.

Thank you also to my colleagues and supervisors in special education and of course the children, without whom none of this research would have been possible.

Thanks to all my friends and family, who have supported me on this journey.

This research project was given ethical approval by the Massey University Human Ethics

Committee: Southern A (Ref No: 11/41) prior to the start of data gathering. 


\section{Table of Contents}

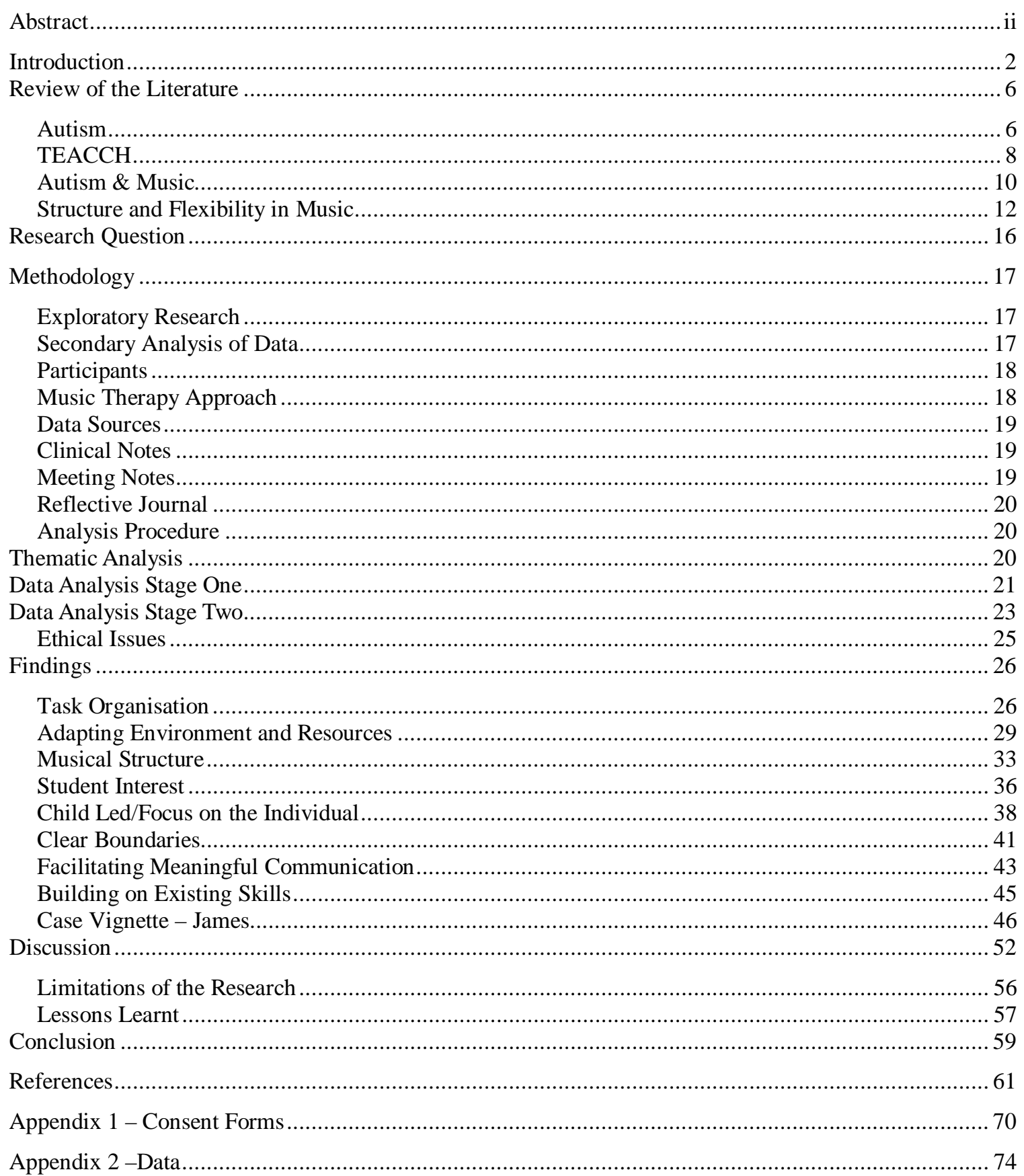




\section{$\underline{\text { Introduction }}$}

This exegesis describes my experiences as a student music therapist at a special needs unit attached to a mainstream primary school within New Zealand. The research is therefore qualitative in nature, and I have chosen to write in first person prose.

The unit supported the learning needs of seven children, most of whom were without functional speech and had a diagnosis of 'classic' autism. Each of the students required assistance from a teacher aide in the learning environment and all were funded by the Ongoing Resourcing Scheme. Funds from the Ongoing Resourcing Scheme are used primarily to provide specialist assistance to meet individual student's learning needs. (Ministry of Education, 2011) The students I worked with had 1:1 support from a teacher aide for a large proportion of the school week. The unit's head teacher had been trained in delivering TEACCH programmes, known as 'Treatment and Education of Autistic and related Communication Handicapped Children’ (Mesibov, Shea \& Schopler, 2005). TEACCH strategies had recently begun to be implemented across the unit in an attempt to support the diverse learning needs of students. This was proving successful within several individual work programmes.

It is important for music therapists to consider aligning their practice with the philosophy and approaches used within the environments in which they work (Pavlicevic \& Ansdell, 2004). It therefore seemed important for me to consider how I might use TEACCH strategies in my work. My wonderings about this led me to focus on the topic throughout 
my time in the unit, and later to review my data for this research project in order to inform other practitioners who might also encounter the approach in their work places. It is important for music therapy practitioners to remain up-to-date with current practice in music therapy and related fields.

The staff members in the unit were supportive and everyone shared a similar philosophy, having the best interests of the students at heart. Several teacher aides had worked in the unit for a long time, so there was a lot of experience and knowledge to draw from and I felt that my evolving practice could develop in safe and well supported way. Furthermore, music groups facilitated by support staff had been an important part of each child's work programme prior to my involvement with the school.

After witnessing the effectiveness of the TEACCH programme in the unit and how the students were able to complete tasks and work independently, I wondered how aspects of TEACCH might then work when applied to a music therapy setting. TEAACH's primary goal is to enable students to function as meaningfully and independently as possible (Mesibov, 2004), and I wondered what this might mean when looking back at the music therapy goals I had applied in the individual assessment phase. These goals included developing shared interaction, reciprocal play and communication (verbal and nonverbal).

In the unit where my research occurred, each student followed a set weekly routine. Staff assessed student's learning styles through observation, trial and error, anecdotal notes in 
individual education plans, specialist input and discussions with parents and family. The learning strategies were then altered to suit the needs of each student. In a number of student work programmes, task boxes had been used daily; a primary TEACCH strategy. Task boxes contain a selection of materials required for a specific task and there is a visual heirachy, which organises the list of activities within the task box. The visual cues and structure provided through the use of task boxes created a safe workspace where expectations are clear. For example, the majority of children in the unit understood the concept of 'finished', through connecting with visual and verbal cues. These verbal cues were able to reinforce that it was time to move onto another activity in their daily schedule. The students I worked with had also learnt that certain activities took place in certain areas within the unit. For example, the familiar environment of the music room appeared to assist in helping students be aware of the expectations and routine of music sessions and also understand that it was in this room that music time took place. As the music therapy programme progressed it seemed to be important to balance the structure of the environment and routine with a space for the development of creative play and spontaneity. This structure and routine appeared to comfort students, whilst creative expression was important for those who were unable to use functional speech as a form of communication. I was therefore interested in exploring how the use of structure, and other recommended TEACCH strategies employed at the school, could be accommodated in individual and group music therapy programmes. Through carrying out this research, I could also improve my learning and highlight the issues surrounding this work. 


\section{My Perceptions of Clinical Work}

I found my music therapy placement to be complex and emotionally charged, but I was confident in my developing practice. I had to form professional relationships with staff and parents and build positive, therapeutic relationships with multiple students. In addition to professional development I had to manage my own personal life and relationships. Practicum was a complex, multi-faceted experience. This study is based on my own training and experiences. My own personal characteristics such as enjoying structure, the quality of learning experiences and the school environment were all variables that influenced my interest in this topic.

Observing TEACCH strategies in the classroom and reviewing the associated literature had the potential to reinforce my natural inclination to use high levels of structure. Therefore critical reflection was important for self-awareness and for making sense of how and why I was working the way I did. Recording reasons as to why sessions were a success or challenge also made my planning more meaningful and child centred. For example, when a student was engaging and responding well I would reflect on how I was facilitating the work and being supportive, along with what I could do going forward to develop these interactions. Reflection can allow a practitioner to learn through experience and to bring together ideas in theory and practice (Fook, 1996 as cited in Barry \& O’Callahan, 2011). 


\section{Review of the Literature}

\section{Autism}

Autism falls under the term 'Autistic Spectrum Disorder' which includes Aspergers Disorder (high functioning autism) and Pervasive Developmental Disorder, not otherwise specified (Lubetsky, Handen \& McGonicle, 2011). Individuals on the spectrum have problems with social development and communication, and can display ritualistic behaviour and resistance to change. (Dimitriadis \& Smeijsters, 2011). The condition ranges from mild to moderate to severe degrees of sensory, communication and social impairment.

'Classic' autism falls at the more severe end of the spectrum. People with classic autism have difficulties with effective speech, which is limited or largely missing, and people are generally oversensitive to their environment (Schopler \& Mesibov, 1988). Additionally, there is likely to be a degree of intellectual impairment and changes in routine can be upsetting, which can in turn result in very ritualistic behaviour.

DSM-IVTR (APA, 2000) describes autism as having three core elements. Firstly there is an impairment in social interaction. This can present in a variety of different ways such as limited eye contact and deficits in gestures used to manage social interactions. 
Developing relationships with peers can be difficult and there is a lack of spontaneity in the seeking of shared enjoyment, interests, or achievements with other people. There can also be impairments in communication. These could include a delay in development, or total lack of the development of verbal language. In individuals with verbal abilities, there is an impairment in the ability to initiate or maintain a conversation with others. Stereotyped and repetitive use of language or a lack of pretend play or social interactions appropriate to developmental level can also be seen. Tomlinson (2010) notes that due to the anxieties surrounding social exchanges, individuals with autism tend to have an innate desire to be in control of their world. However once they are convinced of "the pleasures and empowerment of meaningful interaction, they can often be guided towards acquiring social skills that most individuals take for granted” (p.240). Furthermore, Trevarthen (2002) found that people with autism are highly sensitive to how other people behave. This makes music therapy an ideal treatment because music enables social interaction whilst also being non-confrontational and non-threatening.

Restricted repetitive and stereotyped patterns of behaviour are also a trait. These behaviours may include restricted patterns of interest that are abnormal in intensity or focus, and typical repetitive motor mannerisms such as spinning objects or hand flapping. Greenspan \& Wieder, (2009) observed that these behaviours arise from more fundamental problems in relating, communicating and thinking.

Biological, neurological and etiological factors are believed to play a role in the cause, however no single factor has been proven to produce the disorder. Piccioto and Delwiche 
(2009) report an increase in diagnosis in recent years. While some believe better identification, diagnosis and general awareness is the reason for this, others believe there is an increase in autism and ASD due to neurological and biological factors increasing in general. There is no cure to the disorder, however early intervention can assist in facilitating significant improvements. (Kasari 2002). Music therapy is an intervention that can contribute towards producing these changes for people with autism and their families.

Mavropoulou, Papadopoulou and Kakana (2011) state that independence and selfmanagement are essential curriculum objectives for the education of people with autism. This is because individuals generally rely on caregiver prompting and feedback for completing tasks and making transitions between activities. Ghosh, Koch, Kumar \& Rao, (2009) note that when planning an intervention with a person with autism, "treatment should be tailored to the student's unique strengths, weaknesses and needs” (p.4).

\section{TEACCH}

'Treatment and Education of Autistic and related Communication Handicapped Children' (TEACCH ) was developed from research originating in 1964 conducted by Dr Eric Schopler (Mesibov, Shea \& Schopler, 2005). TEACCH is not restricted to one technique or one method but is a philosophy of services using various techniques and various combinations for people with autism. The approach depends on the various needs and emerging capabilities of the individual and is based on the belief that a structured learning environment is better than a free approach, due to the element of control and 
security that structure provides. The philosophy of TEACCH recommends that people implementing programmes need to have an understanding of autism. There should also be a focus on the individual needs of a person with autism, choosing appropriate adaptations, and having broad based intervention strategies that build on existing skills and interests.

TEACCH aims to develop educational programmes that will provide structure and organisation and improve an individual's communication skills. It is based on three fundamental principals; the need for individual education programmes, environmental adaptation and alternative communication training. Educational programmes, based on detailed assessment, are revised frequently as students mature and progress. Assessments look for student's strengths, to identify what they can do, rather than what they cannot do, across a range of domains. TEACCH programmes are fundamentally different to Behaviour Modification Programmes in that they do not aim just to change behaviour, but the underlying conditions that influence behaviour. If the environment is managed to meet an individual's needs, e.g. by making it (at least initially) more structured and predictable, their anxiety and frustration relating to communication and comprehension difficulties decreases (Matson, 2009).

TEACCH advocates for a focus on the person and the development of a programme structured around the individual's skills, interests and needs. However, TEACCH researchers have found some approaches that appear to have some general application. For example, the use of structure fits the 'culture of autism' effectively (Dodd 2005; Mesibov, Shea \& Schopler, 2005). This study found that a particular focus on physical 
structure, daily schedules, work systems and visual structure within activities could be helpful with students who have autism. Students might have a timetable with symbols or words for each activity during the day. Through utilising this system, the student becomes prepared for changes in activity or environment, and is therefore less traumatised by these things. TEACCH research suggests stress in people with autism decreases as they know what is expected of them (Mesibov, Shea \& Schopler, 2005).

\section{Autism \& Music}

People with autism often respond more frequently and appropriately to music than any other auditory stimulus (Starr \& Zenker, 1998; Keen \& Simpson, 2011; Heaton, Hermelin \& Pring, 1999; Wigram \& Gold, 2006). Because of this, autism has been one of the first and major areas of practice in the application of music therapy. (Gold, 2011; Dimitriadis \& Smeijsters, 2011). Music can reinforce abilities and minimise deficiencies, and the elements of music can enable communication and expression. Music can support positive social interactions, facilitate verbal and non-verbal communication, enhance successoriented opportunities for achievement and mastery, and is often a strength for people with autism (Alvin, 1991; Gottschewski, 2001; Warwick, 1995).

Wigram \& Gold (2006) describe music therapy as a systematic process of intervention wherein the therapist helps the client to promote health, using musical experiences and the relationships that develop through them as dynamic forces of change. Edgerton (1994, as cited in Wigram \& Gold, 2006) examined the development of communicative skills in eleven children with autism over the course of music therapy sessions and noted a 
continuous increase of communicative acts and responses in all subjects. Central music therapy techniques include free and structured improvisation, songs and listening to music. Within a special education context, music therapy can also provide support in areas such as cognitive development, which includes problem solving, remembering sequences and categorical structures (Pelliteri, 2000). Elefant, Gold \& Wigram (2010) note that the process of musical improvisation may help people with ASD to develop the capacity for social interaction and communication skills, in that improvisation is sometimes understood and described as a non-verbal language that enables non-verbal people to interact and engage on a more emotional level. Behaviours such as joint attention, eye contact and turn taking are characteristic events in shared, active music making.

Demaine, Norton, Schlaug, Wan \& Zipse (2010), and Laugeson et. al, (2009) describe how the mirror neuron system can be engaged through the processing of music and discusses music's potential as an educational and therapeutic tool due to its intensely social nature. Demaine et al. (2010) state that "Music is one medium in which the putative MNS can be engaged. Music is a unique multi modal stimulus that involves the processing of simultaneous visual, auditory, somatosensory, and motoric information; in music making, this information is used to execute and control motor actions. It has been suggested that music making activities involving imitation and synchronisation may engage regions of the brain that overlap with regions that presumably contain mirror neurons, music making activities may be particularly useful for the treatment of developmental disorders such as autism” (р.4). 
Fischer-Terworth \& Probst, (2010) also describe in their work with people with dementia how music can been seen as a valuable communication system. Music exerts many effects at the behavioural and emotional level and the authors note the similar neurological characteristics of autism and dementia.

Gattino, Riesgo, Longon, Leite, \& Faccini, (2011) researched the effects of relational music therapy, which is based on individuals developing their capacities in accordance to interactions in the therapeutic setting. In this study music was favoured over standard care when developing the verbal, non-verbal and social communication of people with autism.

Keen \& Simpson’s review (2011) on the benefits of music interventions for people with autism further noted the preference and responses displayed in music based settings. However they concluded that there was still limited evidence to support this intervention under certain conditions to facilitate social, communicative and behavioural development. Accordino, Comer \& Heller (2006) also observed a need for more and better research to support music therapy interventions for individuals with autism. Exploring the connections between music therapy and TEACCH is therefore important for autism, TEACCH and music therapy research.

\section{Structure and Flexibility in Music}

As research into this field has developed, music therapy enquiries have grown to be more 
science based; yet they remain a process that is developmental, musical and interpersonal. (Pavleclivic et al., 2009 as cited in Dimitriadis and Smeijsters, 2011). The qualities and nuances found within music and it's elements offer a means by which a form of alternative and meaningful communication can be established to achieve engagement, interaction and relationships (Wigram \& Gold, 2005).

Heaton, Hermelin \& Pring (1999) observed that children with autism understand the affective connotations of musical mode sufficiently well, being able to associate representations of happy and sad faces with excerpts of music in major and minor keys.

Musical elements such as tempo, dynamic, phrasing, melody and rhythm can create this structural element, allowing for a sense of security to be established. Implementing a structured framework so as to cater for the person's need for routine and predictability may also help in extending their playing and developing attention and expression (Wigram, Pederson \& Bonde, 2002).

Musical elements can also bring about variability and flexibility to go against the repetitive behaviour and resistance to change associated with people with autism and allow for creativity to emerge (Trevarthen, 2002). Creativity in music involves a subtle process of learning patterning within musical structures which can then create a foundation for variability of form, such as in using dynamics and changing tempo. (Wigram \& Gold, 2006)

Frisch (1990) highlights the importance of verbal components to create structure in music 
therapy group work with adolescents. In her work she found that verbal instruction increased the music's efficacy when used in a way that highlighted the musical activities of the work. Gibbons (1983) further explores the use of musical elements to establish structure. It was found that repeating rhythmic activities led to an improvement in internal organisation and impulse control in emotionally disturbed young children.

Walsh-Stewart (2002) also combined music therapy and TEACCH using a psychodynamic music therapy approach. The author investigated increasing communication in children with autism, and concluded that the intervention 'succeeded in stimulating a fresh and creative approach to complement existing resources available in the treatment of children diagnosed with ASD. (Stewart, 2002, p.184).

In Fischer et al.’s (2011) research into using a Music Therapy and TEACCH model when working with people with mild to moderate dementia, it was discovered that structured teaching offered a solid basis for musical interventions. The authors observed that music itself had strong structuring properties, offering a frame of time structure experienced on a sensory level.

Walsh (2002) describes the multi-disciplinary approach of using psychodynamic music therapy and using the TEACCH communication programme to increase socio-emotional communication responses of a student with Autistic Spectrum Disorder, including offering a "structured and flexible environment for student" (p.169).

Wigram (1991) demonstrates the importance of balancing structure and freedom in music 
therapy programmes through a case study description of a girl who has Rett's syndrome, which is a pervasive developmental disorder sometimes included in the Autistic Spectrum. He suggests the student was able to make substantial development after he used a structured and directive approach for eight months, followed by "a longer period, when some of the structure was sustained, but within a more psychodynamic framework which allowed the girl to channel her newly acquired awareness and skills into an expressive and interactive exchange” (p.45). Storey (2005) also notes similar work using aspects of TEACCH with a student with autism who needed structure within sessions. The author states that the student would have found it very difficult to take part in expressive shared playing and singing without a highly structured format.

Wigram (2004) further explored the concept of flexibility in music and observed that through allowing flexibility, the therapist is able to support the client intuitively in the 'here and now' and promote an effective and engaging dialogue.

\section{Summary}

This literature review I have described various features of Autistic Spectrum Disorder, and have suggested that children with ASD respond well to a structured learning environment. TEACCH, which strongly advocates for structure within programmes for children with ASD, is becoming increasingly popular within programmes for this population. I have also argued that music therapy is considered to be a useful approach to use in the treatment of children who have ASD, and that its success seems to be closely 
associated with the structural elements contained within music, and music therapy sessions. I was therefore interested to consider how the elements of TEACCH aligned with the strategies used in music therapy.

\section{Research Question}

Can aspects of the TEACCH philosophy be found in my own music therapy practice in a special education setting?

In this study I attempt to explore whether there is a correlation between aspects of the TEACCH philosophy and my own music therapy practice in this particular setting.

In order to investigate this I describe and critically analyse a particular aspect of my clinical practice. Specifically, I explored my clinical data to determine how structure, and other aspects of TEACCH philosophy, might be found in music therapy programmes within a special education setting. The intention of this study was to improve my learning and to inform other music therapy students and practitioners of the issues involved in this work.. A definite variable in the study is the changes that occurred as I conducted the clinical work and research over the data gathering and analysis phases. This may have been due to my development as both a clinician and researcher. 


\section{Methodology}

\section{Exploratory Research}

This research is exploratory. Exploratory research allows for the researcher to become familiarised with a problem or concept while the research is taking place. It can help determine the best research design, data collection method and selection of subjects; and can be quite informal, relying on reviewing the available literature and/or data (Stebbins, 2001). I chose exploratory research because of my initial limited knowledge of TEACCH strategies. I was also unsure if there would be any connections between TEACCH and my practice when I began this placement. I kept careful notes and adjusted my practice to ensure it was in line with what other staff where doing in the school, and was able to review this clinical data for this research.

\section{Secondary Analysis of Data}

Secondary analysis involves the analysis of historical or comprehensive existing information, to answer a new question (Heaton, 1998). That is, data is re-examined for a purpose other than which it was originally gathered. It is often a starting point for other social science research methods. In this study I used documentation from individual and group sessions, analysing the data I had collected from four-week blocks of practice, to 
uncover TEACCH themes ${ }^{1}$. Following each four-week block of practice I would take two weeks to review the data, before beginning the cycle again.

\section{Participants}

There were no direct research participants in my research, and my music therapy practice occurred in a standard and usual way, as taught by my learning institution. The focus of my research was on how I facilitated sessions and supported students, rather than on how the students were responding to the work. That is, I was not looking at how students were participating and engaging in sessions, but investigating whether and how I incorporated TEACCH strategies in my work, to support the students, by examining the documentation I had collected as part of my usual clinical practice.

\section{Music Therapy Approach}

Of the seven students within the unit, all were involved in group and/or individual music therapy and each had a diagnosis of autism. Each student was classed as having high to very high special education needs, with each bringing their own unique personalities, differing strengths and challenges to sessions. My music therapy was based on a humanistic philosophy and I predominantly used a creative music therapy approach which involved a mix of pre-composed material that was likely to be familiar to the children, and improvised but relatively structured songs.

\footnotetext{
${ }^{1}$ Refer to examples of data analysis in the appendices.
} 


\section{Data Sources}

In this study I used documentation from all of my individual and group sessions.

Following each four-week block of practice I would take two weeks to review the data sources listed below, before beginning the cycle again.

\section{Clinical Notes}

The notes I gathered from sessions were primary data sources for this research. Group sessions were carried out twice weekly and each student took part in a weekly individual music therapy session which occurred at a regular time in their schedule. At the end of each group and individual session, notes were recorded which outlined what had occurred, what I had done to facilitate the work and how students had responded in the sessions.

These notes were gathered as part of usual practice, and reflected the process and development of my own music therapy work. I prepared thorough documentation and recorded the process and musical developments after each weekly individual and twice weekly group session as part of standard practice.

\section{Meeting Notes}

I was also engaged in formal and informal discussions with families and other work 
colleagues. Discussions with multidisciplinary team members provided opportunities to brain storm ideas about how I could best approach the work. Current and historical notes often formed the basis of our discussions.

\section{Reflective Journal}

I would regularly write thoughts and ideas that grew out of how group and individual work was progressing, into a confidential reflective journal. I also reflected on how my ideas, feelings, and skills were affecting my work. Further I used my journal to reflect on meetings with staff. Using this journal was helpful in the development of my thinking and for recording any thoughts around the work that surfaced outside of normal practice hours.

\section{Analysis Procedure}

\section{Thematic Analysis}

Thematic analysis is a method of qualitative analysis. It allows the researcher to report themes or patterns in the data in rich detail (Rickson, 2011; Braun et al., (2006). Aronson (1994) describes the process of thematic analysis occurring over four stages.

Following the procedure outlined by Aronson (1994) I; 
- $\quad$ Read the data several times to ensure I was familiar with the data to be expedited, and gathered some insights. In each stage of analysis the researcher will alter and modify

- $\quad$ Altered and modified the analysis in the light of my experience and as ideas developed.

- $\quad$ Identified examples of each theme to illustrate what the analysis has achieved.

- $\quad$ Defined each theme sufficiently.

- $\quad$ Thematic analysis focuses on identifiable themes and patterns of behaviour.

\section{Data Analysis Stage One}

First I wanted to identify the main themes associated with TEACCH. For this I used an inductive approach. This means I began with no knowledge of what I was looking for, and that I examined the literature thoroughly, and observed individual work programmes where TEACCH was being implemented, allowing the themes to emerge from the data. For example, I observed students being able to manage routines successfully due to consistent schedules and work environments. In the TEACCH literature this is known as task organisation (Kakana et al., 2011).

I analysed this data as a music therapy student who did not have a background of certified training in implementing TEACCH programmes. I was therefore supervised by the unit's special education head teacher who had experience and training in implementing TEACCH strategies. In our discussions there was a focus on catering to the learning 
needs of individual students and how some TEACCH principles were able to support these needs. For example, an important TEACCH principal is using the student's interest to create a learning experience that is relevant to the child. The head teacher noted how using the student's interest was a useful tool to promote engagement in learning. TEACCH has a strong focus on working with an individual's strengths and interests to support learning (Mesibov, 2004). Unlike the classroom observations where identifying TEACCH principles came out of me watching the students, the discussions with the head teacher helped to further connect the gathered TEACCH principals to specific learning situations. I allowed for the broadest possible set of themes to surface which I would then consider later to explore in my practice.

Furthermore, articles were sourced using an online database to cross-check the set of TEACCH themes I found from classroom observations and discussions with existing research. This helped me be confident that the set of TEACCH themes that I had gathered were not just specific to the situation I was working in. This also clarified that the TEACCH framework is a coherent set of principles. I then took notes from these articles and again observed educational practice in the unit. This helped ensure that the themes I had collated were consistent with practice. The outcome of the process above was the establishment of five initial TEACCH themes that I would be looking for in the next phase of research, in my own music therapy practice. 


\section{Data Analysis Stage Two}

In stage two I engaged in deductive analysis to determine whether these same themes could be found in my clinical data derived from both individual and group work across the four six week blocks.

In the two week data analysis phase, clinical notes would be examined and any TEACCH themes seen in the data were then highlighted (see thematic analysis procedure below). For example, if I was exploring the TEACCH theme of using the student's interest and found that I had been using a favourite toy as a way of directing music therapy improvisations; this would then be noted in a data spread sheet under the theme, 'Student Interest'. I would also look into my reflective journal as I was doing with the clinical and meeting notes. I would then highlight any TEACCH strategies seen in my journal. For example I would draw out any ideas that collated with TEACCH strategies or examples of the work I had written about with specific children that related to TEACCH philosophies.

As I developed as a practitioner and the phases progressed, I saw TEACCH themes occurring in a variety of different ways. This was due to the needs, strengths and interests of individuals, how they responded to my music therapy programmes and how I in turn chose to build on their responses in sessions. The way I looked into the data also became more complex as I developed a deeper understanding of TEACCH and grew as a researcher. 
The spread sheets used to assemble examples of the themes from individual and group work were divided up into the four six week blocks. New themes were found in the same way that the initial themes were identified, that is I looked to the literature and what was occurring in individual work programmes within the unit. For example, in phase two, I introduced a new TEACCH theme to explore in my music therapy documentation of ‘Facilitating Meaningful Communication’. I observed, connected my observations with the literature and had discussions with the head teacher so as to link up the literature to specific learning situations in the classroom. I would then explore the concept of communication in my documentation and in the autism and music therapy literature.

The following table shows how each phase developed and how my understanding of TEACCH strategies changed over the data gathering and analysis stages.

\begin{tabular}{|l|l|l|l|}
\hline Phase One & Phase Two & Phase Three & Phase Four \\
\hline 1.Task & 1.Task Organisation & 1.Task Organisation & 1.Task Organisation \\
2.Adapting & 2.Adapting Environment & 2.Adapting Environment & 2.Adapting Environment \\
Environment & 4.Child Led & 3.Musical Structure & 3.Musical Structure \\
3.Musical & 5.Child Interest & 4.Child Led & 4. Child Led \\
Structure & 6.Facilitating Meaningful & 6.Facilitating Meaning & 6.Facilitating Meaning \\
4.Child Interest & Communication & Communication & Communication \\
5.Child Led & & 7.Clear Boundaries & 7.Clear Boundaries \\
& & & 8.Building on Existing \\
& & & Skills \\
\hline
\end{tabular}




\section{Ethical Issues}

Ethical approval was gained for "NZSM Master of Music Therapy Programme ethical template for student research in NZSM 526 undertaken as observational studies, theoretical or case study research” (HEC: Southern A Application 11/41) I also sought informed consent from

1. the facility for the research to take place in the school, and for clinical data to be subjected to secondary analysis for research purposes and

2. From parents of the student I describe later in the case vignette.

Due to the focus being on what I did in the sessions as a whole, rather than an in-depth study of individual treatment programmes, permission was not required from each student and their family for this aspect of the research. The focus was on my practice and what I did, rather than specific students whom I was working with.

There was no expectation that students and/or staff would have to attend any extra sessions, and any meetings with team members or families would be part of the usual liaison process at the school. Data was gathered on site at the unit as part of clinical practice, and the secondary analysis took place at the school or once the data was de-identified and kept on a password protected computer, at my place of study (University or home office). 


\section{Findings}

I will now describe findings drawn from the data analysis.

At each stage of analysis I focused on my growing understanding of TEACCH and investigated whether these themes were being implemented within my standard music therapy practice. The subheadings in this section describe each TEACCH theme examined and how when looking back on music therapy documentation in the unit, they were highlighted within my practice. Examples are included to further emphasise any connections between music therapy and TEACCH.

\section{Task Organisation}

TEACCH suggests that 'task organisation' is important because is assists people in understanding task requirements, sequences of steps and instructions (Kakana et al., 2011). Task organisation helps students to work independently, knowing how many items must be completed along with the subsequent final outcome (Schopler, Mesibov \& Hearsey, 1995). Therefore, students can engage with the task in their own way, errors are

reduced, stereotypic behaviours decrease and learning occurs more quickly (Ferrante, Panerai \& Zingale, 2002).

Aspects of task organisation found in the data include;

1. Establishing and reinforcing group guidelines 
2. 'Hello' and ‘Goodbye’ songs in sessions

3. Implementing familiar routines

4. Establishing positive relationships with staff

1. Establishing and reinforcing group guidelines

Group guidelines for participating staff and myself were established and used consistently throughout the research period. I believed these guidelines would reduce potential distractions for participating students. Guidelines for support workers (such as offering non verbal assistance and minimising visual prompts) seemed to maximise the group experience (productivity) for the students and minimise mixed messages. These guidelines were implemented due to feedback given from the visiting music therapy supervisor.

2. 'Hello' and ‘Goodbye’ songs in sessions

I introduced new hello and goodbye songs that would be used consistently across all group and individual work. While the newness of the songs, the setting, myself as the new therapist and so on, would be difficult for students initially, repeating unfamiliar aspects of sessions were important so as to establish a sense of familiarity, and thus be comforting and provide security for students. 'Hello' and 'Goodbye' songs are an example using task organisation and assist in establishing a schedule in music therapy sessions. Schopler et al (1995) decribes schedules in TEACCH as a way of reducing 
problems relating to time and organisation and they can foster self-motivation and independence.

\section{Implementing familiar routines}

After group and individual work had been established, I changed the routine of group and individual sessions slightly. I felt that it was appropriate to create some manageable challenges within the now established familiar routine. Challenging students with autism is supported by the zone of proximal development, a theory first introduced in the 1930's by Soviet psychologist Lev Vygotsky. The zone of proximal development is where more complex tasks can be achieved by learners with assistance (Vygotsky1978). Greenspan et al., (2006) describes following the student's lead and challenging the student as two sides of the same coin and once an interest has been highlighted it can be used to draw the student further up the developmental ladder. With this in mind, I recognised that it was an appropriate time to introduce some challenges. For example, rather than having all the students sit through the goodbye song, I began to acknowledge each individual student within the group, and when their name was called they could leave the room with the assistance of a support worker. Other students could follow the instruction and do this independently. Once students had become familiar of the routine within an activity, they began to understand the concepts and expectations around it (giving me eye contact on leaving or waving, as was modelled by myself and the support workers throughout the song). However, when I changed the order of when each student was dismissed, several found it challenging to have an aspect of their routine altered and had to manage their 
anxieties surrounding this.

Due to space constraints within the school, it was also necessary for the location of the music space to change, which created a disruption in the student's routine. The move to the new room had the potential to be distressing for the group members, and I needed to increase the amount of musical structure I was employing to minimise the challenges they were facing because of this. To accommodate this environmental change I focused on songs with simple and predictable chord structures, and accompanying activities that were familiar, which had appeared to relieve anxiety in moments of tension across the group and individual work previously.

4. Establishing positive relationships with staff

Establishing positive and open working relationships with other staff in the unit was beneficial in the work. When these lines of communication were clear, there was able to be smooth transitions to and from music therapy sessions. An example of this was a teacher aide giving clear verbal and visual cues as to when music would be occurring in the student's timetable, and myself reinforcing what would next occur in the student's schedule as part of the goodbye song.

\section{Adapting Environment and Resources}

TEACCH suggests that adapting the environment is important so as to cater for the specific special needs and limitations of people with autism. The working space is altered 
by the teacher implementing the TEACCH strategies in accordance to the student's needs. There are specific areas in the classroom laid out for specific tasks (Tissot \& Evans 2010).

Adapting the environment could include;

1. Using appropriate and engaging materials

2. Positioning students appropriately,

3. Removing or introducing new instruments in sessions

4. The concept of a 'finished box'

5. Visual cues.

6. $\quad$ Adapting 'music therapy' resources

1. Using appropriate and engaging materials

Introducing multi-sensory activities proved to be beneficial in the group work environment. A multi-coloured parachute was used in such activities and was very engaging for students. I structured this work with music that reflected the activity, such as improvising a song using words associated with the task. This could also be done with using a rainbow ring, which is a colourful circle shaped piece of elastic, which allowed the group as a whole to share in an activity and have a positive social experience.

\section{Positioning students appropriately}


One way in which the environment was changed to assist in helping the students in working more effectively was using the same blue square music mat consistently. Continuing to use this object cue when the music space needed to be altered seemed to comfort the students and assisted in providing a smooth transition and sense of familiarity.

Positioning students appropriately in group work also aligned with TEACCH's concept of adapting the environment. At one stage, the dynamics between two students began to affect the engagement and participation of themselves and others in group work. Therefore, students were positioned in a way in which these distractions would be minimised and they would have opportunities to participate more effectively. If I thought that objects or obstacles had the potential to be distracting and were going to be in the student's line of sight I would then remove them.

\section{Removing or introducing instruments}

I carefully selected the amount of instruments used appropriate to skill level, and removed objects that had the potential to be distracting. TEACCH emphasises the use of physical boundaries and removing objects and obstacles that have the potential to be distracting (Schultheis, Boswell \& Decker 2000). Through doing this I was able to facilitate work which moved towards having a clear focus and the students seemed to understand what the expectations were. At times using different instruments within sessions provided a change in routine, added variety and gave students a new experience. 


\section{The 'finished' box}

5. Visual cues

Visual cues such as a picture or object cue (drum) are also common in TEACCH and music therapy programmes. Mesibov et al., (2005) note that people with autism have difficulty organizing and sequencing behaviour. Using a finished box makes the concept of finished concrete and meaningful and helps give people a feeling of satisfaction and closure when an activity has been completed. These activities could therefore be generalised once the person has learnt to follow an activity and can be transferred to a variety of settings. In my music therapy work I used a finished box and musical instruments as way of showing a visual 'to do' list. I would also use a drum to show students that is was time for music when I collected them for their session.

\section{Adapting 'music therapy' resources}

The environment and resources used in this setting were also adapted to manage changes in group work when regular support staff could not attend or when new staff were unaware of the group guidelines. When there was less support staff available to assist the students I adapted musically to make it easier to facilitate group tasks, such as managing the parachute when students were unable to do this. My voice also played more of a dominant role in delivering the music which was supporting the group. These sessions were helpful as I was able to learn to use my voice in more effective ways, such as 
becoming more aware of the timbre and dynamics and developing the vocal range. Through this, more observant and intuitive music therapy work seemed to occur and the music was able to happening more naturally while supporting the therapeutic process.

\section{Musical Structure}

TEACCH advocates structuring the environment so as to support the learning processes of students with autism. Structure allows the student to work both independently through work systems and routines and interdependence through communicative and social interaction strategies (Mesibov \& Howley, 2003). Students with autism demonstrate a need for stability so they can feel secure, and within which they can show potential communicativeness and creativity. "The type of music making that occurs spontaneously in music therapy offers this type of 'safe' structure, while still expanding rigid boundaries to achieve greater flexibility" (Wigram \& Gold, 2006, p. 537). The authors also suggest a repetition of ideas, sequences and repeated phrases to ensure that there is some direction and familiarity in the musical material.

Musical structure was used as a way of holding the students in group and individual work. Furthermore it helped experiences be better understood, showing the timeframe of an activity and what the expectation was. Stable and recognisable motifs provided security, and at the same time allowed for creative improvisation within the established structure. 
Aspects of musical structure used in this study included;
1. Harmony
2. Melody
3. Pitch
4. Tempo
5. Dynamics
6. Space/Silence

\section{Harmony}

Finishing a phrasing on a dominant $5^{\text {th }}$ chord or using a seventh chord, similar in its anticipatory quality, gave space and an opportunity for students to respond.

\section{Melody}

I provided ascending and descending scales when singing to support lyrics which were describing movements. For example I supported the words ‘up' and 'down' in a song with appropriate ascending and descending melodic motifs.

\section{Pitch}

I adapted my voice moving from soprano to alto ranges when I observed how different students responded to different ranges within my voice. I also listened to the pitches of vocalisations from students and would mirror and/or build on these with my voice. I also supported these vocalisations on guitar and piano and matched my playing to suit music 
introduced by students.

\section{Tempo}

I observed rhythms of students rocking and other body language and movements, which were used to dictate tempo. I acknowledged agitation through tempo and rhythm or at times would pull back on tempo and upbeat rhythmic patterns to create a calming effect for students.

\section{Dynamics}

I altered dynamics to accommodate for different students sensory needs. For example, for a child who became agitated when hearing loud noises, I would alter my dynamics to suit this. However, at times I would chose to play loudly so as to challenge and assist him in learning to manage sounds outside of the music room.

\section{Space/Silence}

Wigram (2004) and Bunt \& Hoskyns, (2006) note that space is as important as sound is in music making and can provide opportunities for meaningful things to happen.

Silence and space were an aspect of practice that developed over the research. Providing adequate space and silence allowed an appropriate timeframe for students to process information and respond or initiate a new interaction. For example, I added pauses in songs so as to encourage verbal and non-verbal responses and waited for the student to respond when I supported him musically. Space helped myself or the student to redirect the music when a sense of repetitiveness was developing. It also gave space for moments 
of reflection to surface in sessions.

\section{Student Interest}

Many researchers how found that using the student's interest is an effective way to engage and support learning experiences. (Mesibov et al., 2005). Greenspan et al., (2009) states you can teach a student almost anything when her natural interest gives you the window of opportunity and understanding the student's interest will create opportunities to facilitate goal orientated challenges. “Treating a student's seemingly purposeless activity and treating it as purposeful so we can attempt to connect with it is also important” (Greenspan et al., 2009, p. 204).

Using the student's interest allows an experience to be specific to the student and motivates the student to engage and interact.

Aspects of using the student's interest found in the data were;

1. Incorporating the student's name

2. Adapting resources to reflect the individual

3. Familiar songs

4. Providing opportunities for choice making 
1. Incorporating the student's name

Using the student's name frequently in the hello and goodbye song was a simple and effective way to draw the student into the music.

2. Adapting resources to reflect the individual

I used instruments/toys the students were interested in or had brought to the session and incorporated these resources to facilitate more challenging tasks, such as turn taking or changing sequences of events. I attempted to turn a student's perseveration on a tambourine into a meaningful social exchange and supported the with an improvised song that mirrored our actions, finishing on the dominant or tonic chord as the instrument rolled back and forth across the floor. I would also introduce body percussion work for students who enjoyed sensory pressure and touch. In addition, a student who was sensitive to touching and holding objects was encouraged and supported in drumming work so as work towards the sensory processing goals in the student's individual education plan.

Furthermore, when a student walked over and chose to experiment on the piano I would either support their playing, keeping my distance whilst giving rhythmic or vocal support, or I would go and support their playing on the in instrument itself. At times I chose to simply keep my distance and observe. This was dependent on the student's level of interaction and engagement at that specific moment. 


\section{Familiar songs}

Familiar songs were used from student's previous musical experiences . Familiar songs, such as 'Hello' and 'Goodbye' songs can provide recognition and allows for the student to relate to past experiences (Wigram, Pederson \& Bonde 2002).

\section{Providing opportunities for choice making}

I used student notes on file and staff input when selecting instruments that would be appropriate for specific needs and were objects of interest from previous musical experiences. Students were then able to choose from instruments on the mat or from within a task box .

\section{Child Led/Focus on the Individual}

The TEACCH approach includes a focus on the individual with autism and the development of a programme based around the person's skills, interests and needs (Mesibov et al., 2005; Mesibov, 1997). By focusing on the individual the person is the focus rather than the strategies used in the work programme. Individualised assessment is emphasised so as to understand the student better and there is a focus on the 'culture of autism', suggesting the people with autism are part of a distinctive group with common characteristics that are different but not necessarily inferior to the rest of us (Mesibov \& Shea, 2004). Assessment and understanding the culture of autism allows work programmes to be established around where the person is at, making adaptations and 
selecting strategies that utilise the individual's existing skills and interests.

Aspects of being Child led and focusing on the individual included;

1. Student directing sessions musically

2. Providing choice making opportunities

3. Waiting for responses

4. Using appropriate timing

5. Providing opportunities for individualised work in group settings

1. Student directing sessions musically

I improvised around the vocal motifs of the student. I took into account the musical elements of their vocalisations including their pitch and any rhythmic and melodic factors. Creative improvisation or structure could also be established out of any nonverbal communication I observed (smiles, eye contact, agitation, rocking from side to side to the beat of the music). I used spontaneous rhythmic clapping from students which would then drive the tempo of the work and led into music/movement body action songs. I listened to students spontaneously singing and when I couldn’t decipher what was being sung I would support the music with a solid beat, appropriate chords or would sing back what I thought I had heard when space was provided.

2. Providing choice making opportunities 
I incorporated instruments that students chose from the mat or at times what the student was drawn to in the room. I offered choices through using visual objects or verbal cues and I observed what worked for the student and used what the student enjoyed to facilitate more challenging work. One student enjoyed sensory songs with body pressure so this was used to encourage turn taking and reciprocal play in sessions.

\section{Waiting for responses}

Students could also dictate when the music would stop. I would observe what appeared to be solitary play and would attempt to turn it into something reciprocal by mirroring the student and then waiting for a response. An example of this was a student strumming the guitar and whilst they were strumming I would vocalise. When the child would stop strumming I would then stop my singing. I also observed body language and let this direct music. When a student turned away I would stop my playing and wait for student to turn back again, which was when I would continue what I was doing musically.

\section{Using appropriate timing}

I worked at the student's pace and waited for the student to initiate the musical interactions and support these when they occurred. I waited musically and physically and provided space and silence for students to initiate the work. I also gave adequate time and space for reponse and the processing of information. 
5. Providing opportunities for individualised work in group settings

Lal \& Shahane (2011) note that students with autism struggle to learn well in group settings due to differences in skills, learning by imitation and the typical features of autism. However Trevarthen (1997) discusses Nordoff and Robbin's group work with children with autism and the qualities of structured and creatively improvised music drawing participants into a shared musical-emotional experience. Group work was important in this music therapy work as it gave the children a positive social experience and I was able to focus on individuals and improvise around the way each child was engaging.

\section{Clear Boundaries}

Mesibov and Schopler (1994) note that visual and physical boundaries help students understand where each area begins and ends and the relationship between events. Music therapy in this school setting was naturally highly structured due to expectations within the school day and clear boundaries were important.

Providing clear boundaries found in the data included;

1. Having a clear visual space

2. Using music to direct

3. Implementing group guidelines 


\section{Having a clear visual space}

I arranged the music space consistently across all sessions. I used the same blue music mat and removed objects that may have been distracting. I used a sparse room in the first half of the year and moved to another room when the music space was required for another class in the mainstream school. I found it difficult to establish a clear visual space in the new room as this area was used for a multitude of purposes and had the potential to provide a lot of distractions in group and individual work.

\section{Using music to direct}

I discovered in my practice that providing a clear boundary could simply mean providing a clear start and finish with the hello song and goodbye song. In addition, at times I would musically interact with the student when they were in close proximity to the music mat but would if appropriate, stop my playing when they moved away. At times I would draw the student back musically or use a verbal cue to return to the space. It was important for the student to stay in the music space within the time allocated for music, so as to link music therapy sessions with what was appropriate within other activities throughout the school schedule.

3. Guidelines for implementing effective group work

As mentioned in a previous section within this paper, group guidelines were used so as to 
provide consistency in how support staff support supported music therapy sessions and to minimise mixed messages directed towards children. An example of this was asking support staff to use minimal verbal cues. Through implementing this, students would receive verbal cues from one person (myself) and could therefore move towards understanding expectations and instructions more clearly. Support staff were also encouraged to stay for the full length of sessions as leaving part way through appeared to be distracting for students.

\section{Facilitating Meaningful Communication}

Communication in TEACCH is individualised and is drawn from the student's developmental abilities. Mesibov and Shea (2004) note that receptive understanding is the foundation for the expressive use of communication and teaching early communication usually takes the form of associating labels with meaningful, interesting activities in the individual's schedule.

Aspects of facilitating meaningful communication in the data include;

1. Using Visual Cues

2. Using student centred language

3. Drawing from IEP goals

4. Limiting verbal language 


\section{Visual Cues}

I used visual cues to act out songs, such as using animal toys in 'Old MacDonald Had A Farm' I used song cards for a 'to do' list that was arranged from top to bottom. I incorporated the visual prompt of waving in the Goodbye and Hello songs.

\section{Using student centred language}

I used simple language and worded sentences appropriate to developmental level. For example, I attempted be direct when giving instructions and would simplify choice making opportunities to two instruments of song cards, if necessary. In reflection of the work at the end of sessions, I encountered that some challenges and goals that were too complex for the developmental ability of students. I then simplified my planning, such as altering the goodbye song and rewording the lyrics so they were more age appropriate and easier to understand.

\section{Drawing from IEP goals}

In my practice I drew from the IEP goals to understand the development and communicative ability of each student. For example, I regularly used the word 'stop' when providing pauses in songs for a child who needed to understand the word within situations in and out of the school environment. 
4. Limiting verbal language

I used vocalisations as opposed to functional speech in improvisations with students who were non-verbal. I provided opportunities for choice making using simple language, such as asking "red drum or blue drum?”, as opposed to "would you like to play the red drum or the blue drum today?”. Shorter, more direct verbal language appeared to help children with verbal processing.

\section{Building on Existing Skills}

TEACCH focuses on teaching students the process of learning and applying skills with an emphasis on building strengths, interests and emerging skills (Jennett, Harris \& Mesibov, 2003).

It was important to acknowledge the skills of each student and the aspects of sessions that may have presented challenges. Building on existing skills enabled challenges to be incorporated into the work. TEACCH advocates a process that enhances skills and strengths and accepts deficits (Mesibov et al., 2005).

In a music therapy context I observed and recognised differing individual skills and abilities within each student. These included such strengths as students being able to take turns, vocalise and/or contribute verbally, to be able to hold a beater and/or be able to hold a beat. I provided opportunities to focus on areas of strength while allowing for moments where individuals could be challenged. It was helpful to draw from the 
knowledge of other staff in regards to any developing strengths. I also utilised the skills of the support staff and parents, such as them being able to observe from a different perspective and knowing what might work in a broader context.

\section{Summary}

The findings I have described show each of the examined TEACCH strategies surfacing in a variety of ways within music therapy sessions. Reflecting on these TEACCH strategies was helpful as I found out more about the learning processes of individual children and how best to facilitate success orientated music therapy work. TEACCH strategies which stood out at the start of this study included the themes of task organisation and adapting the environment and resources. Providing visual structure through using these strategies helped to create a safe and secure space for the child and myself, as I was developing in confidence and getting to know different personalities. In the later stages of data analysis, themes such as being child led and using musical structure seemed to become more common in the work, as I had developed in confidence and had begun to observe and work more intuitively. .

\section{Case Vignette - James}

James is a seven year old boy with a diagnosis of autism. He likes to order his world through the predictability of routine and his need to control his world is frequently demonstrated by his lack of willingness to follow adult directions. James finds 
transitions difficult so an established routine provides security and predictability for him. He smiles and connects through singing, chanting and familiarity but mainly seeks solitary play whilst demonstrating an awareness of other children. A visual timetable is used in his daily routine to assist in choice making, communicative intent and autonomy. Prior to attending the unit in which I was working, he attended an early intervention centre and worked with a music therapist. Music had been successfully used to help extend his development, particularly his social, emotional and communicative skills. Music was known to help regulate his emotions and allowed him to express himself in a positive way. He had previously enjoyed communicating with others through music and responded with eye contact, vocal sounds and smiles.

I worked with James individually throughout my clinical placement, once a week. He responded to singing and filling gaps in songs and appeared to work well in sessions when his expectations are clear and he understands his daily routine. Goals when working with James included developing his social skills and engaging in activities centred around musical play so as to connect with others and the world around him.

The individual session I will now describe occurred at end of the second term of the school year. James was apprehensive to go to the music room with me that afternoon due to the change in his routine. This was also the first time he had experienced an afternoon session in the recently relocated music room. His support worker went home at midday and the head teacher suggested changing his music time to provide a 1:1 social activity that he enjoyed for the afternoon. On entering the room James appeared to be upset and 
went to the corner of the room, hiding under a blanket. I sat on the mat, waiting for him to come to me and initiate an interaction. After a few minutes I began playing a popular song that was familiar to him on my guitar. His mother had mentioned to me earlier in the week that he was fascinated by this song so we had listened to it at the end of the last session. I began playing this on guitar and it seemed that a combination of my animated singing whilst providing long pauses in the melody drew him to the music mat, where he sat next to me. He was able to fill in gaps in the song where I left spaces for him to do so and sang the final melodic phrase of the song. We then sung the hello song briefly as a way of commencing the session and then sung 'Old Mac Donald' on the mat, with James adding the appropriate animal sounds. This had proved to be a popular and engaging choice for him in previous sessions. James then went and sat at the piano and I followed him. He started singing the up and down song which he had introduced to the session previously and was becoming an obsession for him. I played this briefly but changed the melody of his up and down song and began singing the melodic line of Hey Soul Sister at the piano. I played the chord progression without using my voice and James was able to sing clearly the melodic line with the lyrics 'up' and 'down'. James was now sitting up at the piano, rather than lying down on the stool, so I felt it was important to give him an activity which might encourage him to engage in singing or exploring at the piano. I played the familiar song 'James Brought A Toy Train To Music' and left gaps and pauses where he was able to respond either vocally "toot toot' or playing toots on the piano (2 CDE chords which I had previously modelled to him).

S.

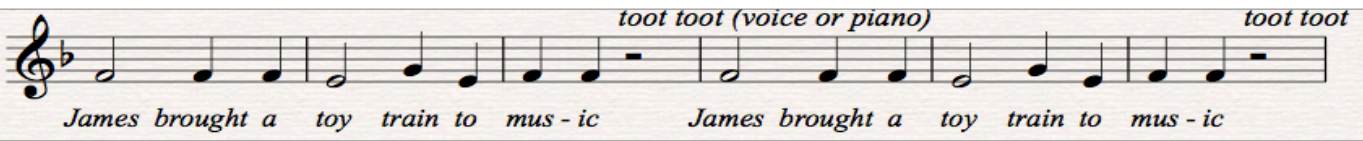


He appeared to enjoy this activity and it then gave him space to explore the piano more. We were then able to improvise for a few moments and he appeared to become more creative in his play. The session was closed with the goodbye song which James memorised quickly and sang along in parts. I waited for his response in the pauses which I had provided. He said "Bye Pip” and he left the music room.

A variety of TEACCH strategies can be found within this session with James.

\section{Task Organisation}

There was a change in James routine with his support worker leaving at midday through the school year. Music therapy was moved from the morning to the afternoon to relieve any potential anxiety surrounding the changes and to provide a one on one activity which James enjoyed. Singing a 'Hello' song gave a clear start to the session which James was familiar with and provided a routine that was consistent with previous morning sessions. James anxiety was reduced when he understood what his routine was in music therapy work. He had to manage these anxieties when his routine was disrupted or I chose to incorporate new activities or challenges such as changing lyrics of a familiar song.

2. Adapting the environment

A blue music mat was used consistently across all sessions which also provided a similar environment to that of previous morning sessions. I also provided spaces in the music 
and waited for James on the mat to come forward and initiate an interaction. James would become easily distracted in the new music room due to it's multiple uses and the subsequent distractions because of this. Setting up the room appropriately and removing objects that were potentially distracting was important so as to assist James in remaining focused and engaged on these music based activities.

\section{Musical Structure}

Providing opportunities for James to fill in gaps in familiar songs, and giving space and anticipation in the music encouraged James to participate and engage with confidence. When he began to repetitively sing his 'Up and Down' song, I changed the melody to counteract this behaviour. At the end of the session I used space and silence in the 'Goodbye’ song to give him adequate time and space to respond.

\section{Student led/Focusing on the individual}

Following James’ led was important in the work for several reasons. Allowing James to lead and direct sessions seemed to decrease his anxiety and gave him a sense of control, within which he was able to engage and respond more effectively, Being 'student led' also seemed to give James a significant amount of pleasure. For example when I joined in with one of his games and followed his lead in the play, it would regularly progress into a highly enjoyable social experience for James and myself, and challenges could then be built around this. Listening to James and staying focused on his playing as opposed my 
own was important and this skill improved as I developed as a musician and an improviser. When James introduced songs to sessions through humming, singing phrases, reciting lyrics or picking up toys that were related to familiar songs or activities, I would support these spontaneous moments and attempt to build on them. Throughout the planning stages of this work with James, I took a shift from using a structured and prepared list of activities to being able to work spontaneously and 'in the moment', so as to fully use these contributions from him.

\section{Using the Student's Interest}

Using popular songs that were familiar to him gave James the confidence to initiate the interactions and drew him into the music space. Familiar songs that James enjoyed gave a clear start and finish to an activity and James knew what to expect in the moment and how long an activity would last for. Music was also a strength and interest for James and these songs seemed to play a part in relieving anxiety when I introduced challenges in the work. Cohen (1993) discusses how it is important for children to experience play in order to understand basic concepts of communication. "By being socialised into the game, the student is socialised into many basic exchanges of life” (p.104). 


\section{Discussion}

Findings suggest that many elements of this music therapy practice align with aspects of TEACCH. TEACCH and my music therapy practice became more connected as I developed as a practitioner. A range of TEACCH strategies became visible depending on how I chose to facilitate sessions according to individual student's strengths, needs and interests.

TEACCH advocates structure to support the learning experiences of people with autism, and music therapy is an active approach that contains many different levels of structure. Children are encouraged to musically explore their own comfort zone, strengths and interests. Music therapy promotes engagement and motivation that can lead to an improvement in communication, social skills, tactile and auditory processing, and other challenging factors associated with autism.

When I began to observe class activities, students seemed to have an understanding of what the expectations were in structured 'TEACCH' based activities. The security that the TEACCH structure provided also seemed to be an effective means of establishing a positive and safe therapeutic relationship in a music therapy context. For example having a schedule for individual and group sessions, using familiar songs and a consistent music space provided security for the students. This enabled children to engage more effectively with tasks, in group work with children and in the individual work. However, the unstructured, more child led approach I implemented in sessions towards the end of 
the study seemed to allow students to explore creatively and engage in a more spontaneous way.

Alvin and Warwick (1991) describe the music therapy process with students as being divided up into different stages, moving from an unstructured to a structured way of working as directed by the therapist. The first stages involve the student and their independent exploration of the instruments and gradually progresses to where a sense of trust in the therapist is established. Gradually the therapist increases their musical and verbal contributions, supporting the student's exploration while providing structure, supporting the “demands made by music itself” (p.23).

Amelia Oldfield (1995) noted that there was a balance between following the student and initiating the interaction and the decision of the therapist to work in a directive and/or non-directive way . "The correct balance between directive and non-directive work can be used towards therapeutic ends by the music therapist” (p. 237).

At the start of this research I wondered what connections there would be between TEAACH and my music therapy practice. For example I wondered how TEACCH and it's primary goal of creating independence might be related to my music therapy goals. For example, my initial goals for students included the development of social interaction and communication through reciprocal play. At first I had difficulty understanding the connection between directing the students to work independently through TEACCH strategies and improving social experiences in the music therapy room. However at the 
later stages of analysis I concluded that when I had provided opportunities in the music through using structure or space, many of the students had moved towards initiating interactions and engaging independently.

Stopping and starting in the data gathering and analysis phases affected my practice and the findings gathered. I was able to be self-reflective of the data and the decisions I was making in the sessions as a practitioner and develop my ideas as I analysed the data, which affected how I was working. I was also getting to know what worked and what didn’t for each individual student which would have affected the research and what I chose to do in sessions. By the end of cycle four TEACCH strategies appeared to be becoming more and more engrained in the work.

At times I felt I was becoming stuck in my own particular way of working. Also, with TEACCH strategies being a major aspect of this research, my decisions were at times driven by my growing knowledge of these principles, rather than what was most appropriate for the child therapeutically in the moment. However, as I learnt more about the students I developed an awareness of what type of musical structure worked for each student and I could support, direct or create further challenges musically. Therefore, because I could direct children to work in a way that was in my view effective, at times my practice felt quite repetitive. I believed taking risks musically may have disrupted the routine and predictability that had been created for the students. On reflection I could have set more challenging goals for the students and could have been more open to risk taking in sessions.. 
Finding meaning in chaotic moments was an important aspect of my learning. I became aware of the importance of interpreting and explaining 'messy' moments to parents, teachers and other members of the multi-disciplinary team. These aspects of sessions at times were more beneficial for students than adhering to a structured way of working. I grew in confidence with finding meaning in those messy moments but could implement further structure when I felt it was necessary. Furthermore, implementing high levels structure, particularly in group work when there were several personalities to support, allowed for the facilitation of a range of achievable challenges.

Overall I believe that increasingly effective work was implemented throughout the course of this research. My ability to be intuitive grew and I learnt to adapt according to the needs of individual students using improvisation techniques, which aligned with the TEACCH approach of being child led and focusing on the individual. My perceptions when observing and interpreting non-verbal communication such as body language also changed and developed. As I continued to mature, understand individual characteristics and interpret what was happening in sessions I continued to find aspects of TEACCH in the work.

As I developed professionally and personally, through reading more literature, developing as an improviser, and becoming more confident, TEACCH strategies were increasingly prevalent in the work. It is therefore possible that if a more experienced music therapist was to explore how TEACCH was connected to their own practice then they may find that TEACCH themes are part of general 'usual' music therapy practice 
anyway. In a setting where TEACCH is strongly represented, music therapists could liaise with TEACCH practitioners on how to use music and its structural elements to further support the visual structure provided in individual work programmes. Additionally, when working with children who strongly responded to music, music strategies could be used to further support learning experiences. For example, music can be used to support the child's broader interests, which is one of the TEACCH themes explored in this study.

\section{Limitations of the Research}

This research enabled me to explore and connect the TEACCH literature and practices of the unit I was working in, to my music therapy practice. This is important because music therapy is a new discipline and it is helpful to be able to demonstrate that it fits well with the philosophy of existing programmes.

There are however, limitations to research of this type. Firstly, I was working with a small number of children and this would have affected the variety of ways in which I chose to carry out sessions. My increasing knowledge of TEACCH, autism and my professional development over the course of the study resulted in increasingly richer clinical records, and thus research findings, over the course of the research.

Time was also a limitation in this study. Children were seen once a week for thirty minutes over the two days I spent as a student music therapist in the unit. My approaches and the data gathered could have changed had students been given the opportunity to 
have had music therapy sessions at different times over the school day and week. The behavioural state of students at different times over the school day could have affected the way I worked and how TEACCH strategies emerged in the work. In addition, I was limited to using existing data. I might have been able to find out more if I could have gathered data in more direct ways, such as interviews. Furthermore a more experienced music therapist and researcher may have gathered more in-depth data.

\section{Lessons Learnt}

Throughout this research I became more confident as a practitioner. I developed a deeper understanding of what was occurring in a given moment and worked in a child centred manner. I believe my ability to develop positive professional relationships quickly with both staff and students were beneficial. Despite feeling disempowered when things went 'wrong' in sessions I felt listening to staff and taking on board feedback from the

multidisciplinary team helped me learn to observe and analyse in a multi-faceted way. I learnt to pay attention to the smaller details and to push and hold back when appropriate.. I learnt to not be consistently expecting constant progress from students. This relates to TEACCH's philosophy of accepting deficits (Mesibov et al., 2005). I developed my understanding in finding meaning in 'messy' moments.. For example, when I saw a student beginning to obsess with an object and appearing not to engage with me, I was able to consider the experience from other views as well. Working therapeutically developed over time as I got to know and understand each student better. 
In my reflective journal a strong theme emerged of TEACCH aligning with aspects of my personality and how I chose to facilitate work. I enjoyed the control and structure that TEACCH brought to sessions and thought it might help in supporting the student towards reaching session goals with more independence. I also had to also learn to be a flexible, responsive clinician who was open to risk taking and losing the structure that I was comfortable with.

Several aspects of my practice could been altered during the data gathering period of this research. Firstly, the wider multi disciplinary team could have been used to greater effect, such as the visiting speech and language and occupational therapists. Their input could have provided further insight and richer data. Their knowledge and experience could have assisted in creating even more effective music therapy sessions. However due to time constraints of my placement and undertaking a part-time role within the school, finding convenient times to meet with other specialist support staff proved difficult and did not eventuate.

Families could have been incorporated more formally into sessions and I could have used the school's 'open door' policy to greater effect. This would have allowed to me gather up to date information on students in a formal way and family centred way. This would have also provided opportunities to develop my professional language and for the families to observe their child being supported in a music making context. Finally, it may have been beneficial to have had an opportunity to work with students in the mainstream setting with higher functioning autism. 


\section{Conclusion}

The elements of TEACCH appeared to be increasingly dominant within my music therapy practice as I became more experienced, and it is clear that both TEACCH and the music therapy model I have been trained in share a similar philosophy. TEACCH is a service, training and research programme that promotes structure and has a focus on the individual's skills, interests and needs, towards independence in and out of the learning environment. The structure and flexibility in music therapy and the elements of music provide a means for establishing the security and predictability that children with autism enjoy. Furthermore, music therapy is able to provide opportunities for spontaneity and creatively which counteract the rigid behaviour and repetitiveness associated with people with autism. At the start of this study themes such as ‘task organisation' and 'adapting the environment' were regularly seen to be used in the music therapy work. As I developed as a practitioner, additional themes such as 'following the child's lead', 'using the child's interest' and 'using musical structure' developed and could be seen more widely. In turn, more effective sessions were occurring. Furthermore, it is possible that these aspects of TEACCH are part of 'usual' practice for more experienced music therapists.

TEACCH was used in a variety of situations in music therapy sessions and different strategies were altered and used depending on the needs of the individual. TEACCH principles such as promoting the use of structure appear to suit how I work. This suggests that different music therapists will emphasise different aspects of TEACCH. This 
research has highlighted the importance of allowing for freedom, spontaneity and taking more risks in sessions. 


\section{References}

Accordino, R., Comer, R., \& Heller, W. (2007). Searching for music’s potential:A critical examination of research on music therapy with individuals with Autism. Research in Autism Spectrum Disorders , 1(1), 101-114.

Allen, R. \& Heaton, P. (2010). Autism, music and the therapeutic potential of music in alexithymia. Music Perception, 27 (4), 251-261.

Alvin, J. \& A Warwick. (1991). Music Therapy for the Autistic Child: Oxford University Press.

American Psychiatric Association. (2000). Diagnostic and statistical manual of mental disorders ( $4^{\text {th }}$ ed., text revision). Washington, DC: American Psychiatric Association.

Aronson, J. (1994). A pragmatic view of thematic analysis. Retrieved from http://www.nova.edu/ssss/QR/BackIssues/QR2-1/aronson.html

Barry, P., \& O'Callaghan, C. (2008). Reflective journal writing. Nordic Journal of Music Therapy, 17(1), 55-66.

Bruscia, K. (1982). Music in the treatment of echolalia. Music Therapy Journal; 2 (1), 
Demaine, K., Norton, A., Schlaug, G., Wan, C., \& Zipse, L. (2010). From music making to speaking: Engaging the mirror neuron system in autism. Brain Res Bull; 82 (34), 161-168.

Dimitriadis, T., \& Smeijsters, H. (2011). Autistic spectrum disorder and music therapy: Theory underpinning practice. Nordic Journal of Music Therapy , 20(2), 108122.

Dodd, S. (2005). Understanding Autism. Elsevier Australia.

Edgerton, C. (1994). The effect of improvisational music therapy on the communicative behaviours of autistic children. Journal of Music Therapy; 31 (1), 31-62.

Elefant, C., Gold, C., \& Wigram, T. (2010). Music Therapy for Autistic Spectrum Disorder (A Review). The Cochrane Collaboration. Published by John Wiley and Sons LTD.

Ferrante, L., Panerai, S., \& Zingale, M. (2002). Benefits of the treatment and education of autistic and communication handicapped children (TEACCH) programme as 
compared with a non-specific approach. Journal of Intellectual Disability Research 46 (4), 318-327.

Fischer-Terworth, C., \& Probst, P. (2011). Evaluation of a TEACCH and music therapy based psychological intervention in mild to moderate dementia. GeroPsych, 24 (2), 93-101.

Fook, J. (1996). The Reflective Researcher: Social Workers ' Experience with Theories of Practice Research. Sydney: Allen \& Unwin.

Frisch, A. (1990). Symbol and structure: music therapy for the adolescent psychiatric inpatient. Music Therapy, 9 (1), 16-33.

Gattino, G., Riesgo, R., Longon, D., Leite, J., \& Faccini, L. (2011). Effects of relational music therapy on communication of children with Autism: a randomised control study. Nordic Journal of Music Therapy, 20(2), 142-154.

Ghosh, S., Koch, M., Kumar, S., \& Rao, A (2009) Review: Do alternative therapies have a role in autism? Online Journal of Health and Allied Sciences , 8, (4), 1-6.

Gibbons, A.C. (1983). Rhythm responses in emotionally disturbed children with differing needs for external structure. Music Therapy, 3 (1), 94-102. 
Gold, C. (2011). Special section: Music therapy for people with autistic spectrum disorder. Nordic Journal of Music Therapy , 20(2), 105-107.

Gottschewski, K. (2001). Autismus aus der Innenperspektive und Musiktherapie [Autism from an inside-out perspective and music therapy]. In D. Aldridge (Ed.), Kairos V: Musiktherapie mit Kindern: Beiträge zur Musiktherapie in der Medizin (pp. 40-57). Bern; Goettingen; Toronto; Seattle: Verlag Hans Huber.

Greenspan, S. I., \& Wieder, S. (2009). Engaging Autism, Using the Floortime Approach to Help Children Relate, Communicate, and Think. Da Capo Lifelong Books.

Heaton, J. (1998). Secondary analysis of qualitative data. Retrieved from http://sru.soc.surrey.ac.uk/SRU22.html

Jennett, H., Harris, S. \& Mesibov, G. (2003). Commitment to philosophy, teacher efficiency and burnout among teachers of children with autism. J Autism Dev Disord. 33(6), 583-93.

Kasari, K. (2002). Assessing change in early intervention programs for children with autism. Journal of Autism and Developmental Disorders, Vol. 32, (5), 447461. 
Keen, D., \& Simpson, K. (2011). Music interventions for children with autism: Narrative review of the literature. J Autism Dev Disord, 41(11), 1507-1514.

Lal, R., \& Shahane, A. (2011). TEACCH Intervention for Autism, (9), 169. Williams, T. (2011). Autism spectrum disorders - from genes to environment. Intech.

Laugeson, E., Molnar-Szakacs, I., Overy, K., Piggot, J., Wang, M. \& Wu., W (2009). Autism, emotion recognition and the mirror neuron system: The case of music. McGill Journal of Medicine, 12(2), 87-98.

Lubetsky, M. J., Handen, B. L. \& McGonigle, J. J., (2011). Autism spectrum disorder. Oxford Univ Pr.

Matson, J. (2009). Applied Behavior Analysis for Children with Autism Spectrum Disorders. Springer New York.

Mavropoulou, S., Papadopoulou, E., \& Kakana, D. (2011). Effects of task organisation on the independent play of students with autism spectrum disorders. J Autism Dev Disord 42; 931-925.

Mesibov, G. (1997). Formal and informal measures on the effectiveness of the TEACCH programme. Autism, 1, 25-35.

Mesibov, G. \& Shea, V. (2010). The TEACCH program in the era of evidence-based 
practice. J Autism Dev Disord 40; 570-579.

Mesibov, G. B., Shea, V., \& Schopler, E. (2005). The TEACCH Approach To Autism Spectrum Disorders. Kluwer Academic/Plenum Publishers.

Schopler, E \& Mesibov, G (1998) Diagnosis and Assessment in Autism. Plenum Press

Ministry of Education. (2000). Teaching Students With Autism; A Resource Guide For Schools. Ministry of Education British Columbia.

Ministry of Education. (2011). Introduction to ORS; The Ongoing Resource Scheme. Ministry of Education New Zealand. Retrieved from http://www.minedu.govt.nz/NZEducation/EducationPolicies/SpecialEducation/Se rvicesAndFunding/ORSOngoingResourcingScheme/ORS.aspx

Oasi, A., Raglio, A., \& Traficante, D. (2011). Autism and music therapy: Intersubjective approach and music therapy assessment. Nordic Journal of Music Therapy., 20(2), 123-141.

Pavlicevic, M. (1997). Music Therapy in Context: Music, Meaning and Relationship. London: Jessica Kingsley Publishers.

Pavlicevic, M., \& Ansdell, G. (2004). Community Music Therapy. London: Jessica 
Kingley Publishers.

Pelliteri, J. (2000). Music therapy in the special education setting. Journal of Educational and Psychological Consultation, 11(3-4), 379-391.

Schultheis, S. F., Boswell, B.B., \& Decker, J. (2000). Successful physical activity programming for students with autism. Focus on Autism \& Other Developmental Disabilities, 15(3), 159-162.

Simpson, R. (2005). Evidence-based practices and students with autism spectrum disorders. Focus on Autism and Other Developmental Disabilities, 20(5), 140149.

Starr, E., \& Zenker, E. (1998). Understanding autism in the context of music therapy: Bridging theory and practice. Canadian Journal of Music Therapy, 6, 1-19.

Schopler, E., Mesibov, G. B., Hearsey, K. (1995). Structured teaching in the TEACCH system. In E. Schopler \& G. B. Mesibov (Eds.), Learning and cognition in autism. 243-267. New York: Kluwer Academic/Plenum.

Stebbins, R. (2001). Exploratory research in the social sciences. Sage Publications.

Storey, J. (2005). The development of a school's music therapy service with an 
illustrative case study of work with a student with Autism. Music Therapy Today Vol VI, 4 musictherapyworld.net

Tomlinson, J. (2009) Music Therapy for Children with Autism in an Educational Context Chap 13. Pg 231. In Karkou, V., \& Karkou, V. (2010). Arts Therapies in Schools, Research and Practice. Jessica Kingsley Pub.

Trevarthen, C. (2002). Autism, sympathy of motives and music therapy. Enfance, 2002/1(54), 86-99.

Trevarthen, C. (1998). Children with Autism, Diagnosis and Interventions to Meet Their Needs. Jessica Kingsley Pub.

Vygotsky, L.S. (1978). Mind and Society: The Development of Higher Psychological Processes. Cambridge, MA: Harvard University Press.

Walsh-Stewart, K. (2002). Increasing Social-Emotional Communication with Children with Autistic Spectrum Disorder using Psychodynamic Music Therapy and Division TEACCH Communication Programme. Chap 11. Pg 164. In Davies, A \& Richards, E (2002) Music Therapy and Group Work: Sound Company. Jessica Kingley Publishers.

Warwick, A. (1995). Music therapy in the education service: research with autistic 
children and their mothers. In T. Wigram, B. Saperston, and R. West (eds) The Art and Science of Music Therapy: A Handbook, 209-225.

Wigram, T. (1991). Music therapy for a girl with Rett's syndrome: balancing structure and freedom. In K. E. Bruscia (Ed.), Case Studies in Music Therapy, 39-53. Phoenixville, PA 19460: Barcelona Publishers.

Wigram, T., Pederson, I. N., \& Bonde, L. O. (2002). A comprehensive guide to music therapy: theory, clinical practice, research and training. London: Jessica Kingsley Publishers. 


\title{
Appendix 1 - Consent Forms
}

\author{
Information Sheet
}

'How Can Aspects of TEACCH Be Incorporated Into Music Therapy Programmes within a Special Education Setting'

Dear.

I am a Master of Music Therapy student working in the special educational facility at

As part of my training I am required to look back at the work I have done with the children and write a research paper on my findings.

I am looking into how structured teaching (also known as TEACCH) and music therapy work together within a school setting. My research process involves looking back over the notes I have recorded after each session, to find out how I have used TEACCH principles in my work. My lecturers have also asked me to include one or two specific examples of work with students, to illustrate what I am writing about. I am also required to present a case, verbally, at my final exam. The information about this case would only be heard by music therapy staff and students of the NZSM, and examiners, in a confidential environment.

I am writing to ask two things:

Firstly, I want to know if I can look back over the notes I have written about my work with your child.... to illustrate my findings. I will be asking the parents or caregivers of about six children the same thing, so it is ok if you prefer not to do this. I will choose to write about the first two children whose parents agree that it is ok, so it might not be possible to write about your child.

Secondly, I want to know if I can talk about my work with your child at my final exam.

If I do write about your child, I will not use their real name in my work, unless you especially ask me to, and I will keep the consent forms in a locked cupboard at New Zealand School of Music. I will give a full copy of my research to the findings.

If you agree to me writing about my work with your child, or to talking about my work with your child at my final exam, please sign the consent form (attached) and return it to

Please take as much time as you need to think about this before signing the form, and ask as many questions as you need to, at any time. Even if you sign the form you can change your mind up until the time that I have finished all the data analysis, i.e. September $30^{\text {th }}$.

If you have any questions or concerns please feel free to talk to supervisor (name below)

\section{or myself, or my}

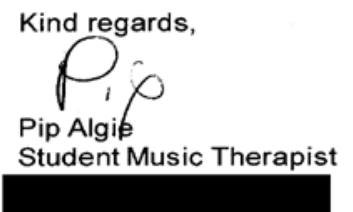

Supervisor:

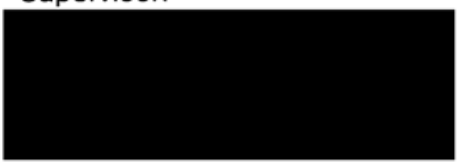


Consent Form

'How Can Aspects of TEACCH Be Incorporated Into Music Therapy Programmes within a Special Education Setting'

I have read the information sheet about the above study and I understand what it is about.

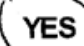

NO

I have asked all the questions I need to ask and know that I can ask further questions at any time.

I give consent for Pip to look back over the notes she has written about her work with (child's name), and to use information from these notes to illustrate her research findings.

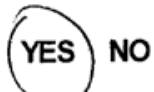

I give consent for Pip to talk about her music therapy work with (child's name)

...................., in class, and at her music therapy examination.
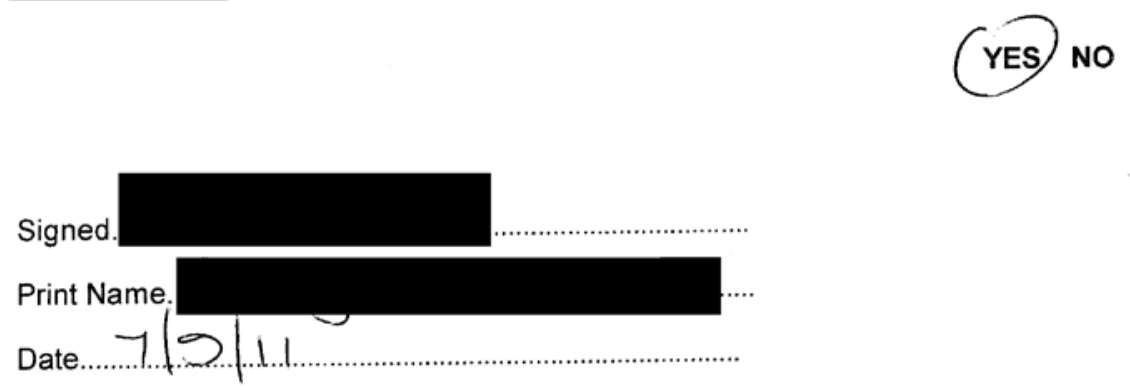
Information Sheet

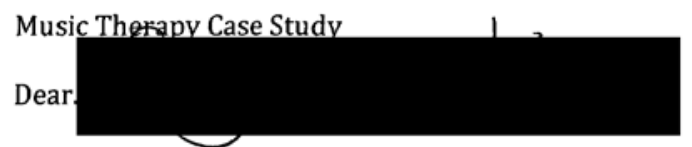

I am a Master of Music Therapy student working in the special educational facility at As you know, I have been working with your child,

As part of my training I am required to present a case study about my work with a child, verbally, at my final exam. The information about this case would only be heard by music therapy staff and students of the NZSM in class, and examiners at the final exam, in a confidential environment.

I am writing to ask if I can talk about sign the consent form (attached) and return it to

atmvexamination. If you agree, please Please take as much time as you need to think about this before signing the form, and ask as many questions as you need to, at any time.

If you have any questions or concerns please feel free to talk to supervisor (name below)

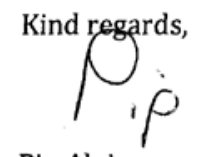

Pip Algie

Student Music Therapist

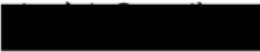

Supervisor:

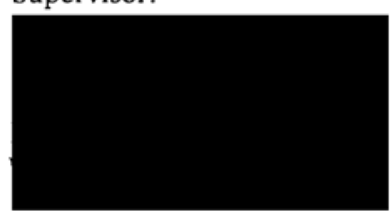




\section{Consent Form}

Music Therapy Case Study

I have read the information sheet about the above study and I understand what it is about.

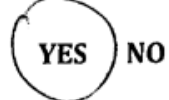

I have asked all the questions I need to ask and know that I can ask further questions at any time.

(YES NO

I give consent for Pip to talk about her music therapy work with (child's name)

.........., in class, and at her music therapy examination.

(YES) NO

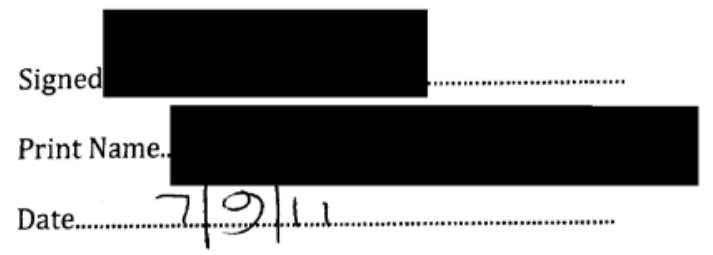




\section{Appendix 2 -Data}

\section{Phase 1}

\section{Task Organisation}

Using pecs board to let him know when music is and communicating with teacher aide to ensure smooth transition Using structure that

already works from case notes

Hello song and goodbye

song to encourage

language

Verbal cues and responding to directions

\section{Adapting}

Resources

Using donut (enclosed space L

enjoys) to help build a

relationship and interact with

him

Picking instruments he is likely

to engage with

Using body percussion as he

enjoys sensory pressure

Removing donut and

encouraging him to sit on the

music mat

Moving donut to within the

music space

\section{Musical Structure}

Responding to the high pitched descending 5ths w/in

the music

Providing gaps in music to

encourage response.

Improvising around interest

Using 7th chords in music to encourage response

Familiar song structures allow him to experiment in other ways(w/ musical

instruments) without getting anxious

\section{Phase 2}

Becoming familiar with

the hello and goodbye

song

Singing "play time next

story with name then

music with Pip" to

reinforce routine.

Understand and calm

anxiety
Using piano and turn taking activities to draw him into the music space

providing opportunities for joint singing

\section{Child Interest}

Familiar songs to engage and relaxfrom former clinical notes

Exploring the shape of the guitar as I played

Incorporating a toy he was playing with

Talking to Mum to find out what he enjoys at home and responds to

\section{Child centred language}

Facilitating meaningful communication
Difference between

distraction and interest

Challenging him by introducing other resources (instruments)

\section{Bringing in train and}

improvising a song with 'toots'
Keeping language simple so he dosnt become echolalic and anxious

Singing lines of songs to direct where session will go

Child enjoys dancing so incorporating music and movement in sessions

Listening to vocalisations

to hear what songs he wants

to sing

Copying vocal motifs and

turning them into

improvised songs 
